\title{
CONFLICT AND IDENTITY AS A MAJOR IMPETUS IN ESCALATING OR DE-ESCALATING CONFLICT
}

\author{
Jared O. Bell \\ International University of Sarajevo
}

\begin{abstract}
Identity is a complex phenomenon and so is conflict. When examining the two together we can understand why some of the world's most difficult ethnic conflicts are long term and protracted. This paper aims to analyze how identity and conflict could prevent and manage conflicts, caused by different perceptions of the identity. After all, identity can be used to escalate conflicts and connected with power and resources, identity can also be used to de-escalate conflicts as well. The purpose of this paper is to make a comparative study of the relationship between identity and conflict.
\end{abstract}

Keywords: Conflict; Identity; Power; Conflict Resolution.

\section{The Relationship between Identity and Conflict}

Identity and conflict are inextricably linked. Throughout our lives, even before we are old enough to comprehend what we are being taught, we are socialized to believe in a series of established set of ideas, principles, values, and belief systems which come to constitute not only our culture, but in many cases our national, ethnic, and religious identities. This is what social scientists across many disciplines have termed the collective identity. According to Midlarsky (2000)

People with collective identities or ethnicities typically share common proper names, a myth of common ancestry that denotes common origin in time and a place, shared historical memories in the form of shared memories of a common past, elements of a common culture tend to include religion, customs, and language, a link with a homeland imagined or real, and a sense of solidarity (p. 26).

These identities become one of the foremost ways we come to make senses of not only ourselves, but, the rest of the world. Pruitt and Kim (2004) maintain that, when people identify themselves with a particular group, they find favor with their own group, its members, and favor one's own group in order to enhance their self-esteem, which is part 
of the social identity theory. Furthermore, Pruitt and Kim (2004) also argue that inter-group conflicts occur when these different groups frustrate each other's goals and/or aspirations (p. 30). Folger, Poole, and Stuntman (2009) add to this point by asserting that the impetus of intergroup conflict lies in the fundamental human necessity for identity. Social categorization therefore is the, basic social process whereby people define themselves by identifying the groups that they and others belong to (p. 92). Folgers et. al., also (2009) points to the importance of not only how our membership in certain groups defines us, but how our lack of membership, in other groups, is equally as important (p. 92)

One of the most dominating senses of identity that has caused conflict is nationalism, in particular civic nationalism and ethnonationalism. Religious identity may also be a great source of conflict and can be wed with the two other terms, especially ethno-nationalism. Moreover, civic nationalism is based around state sovereignty. This form of nationalism is based on individual citizenship, which demands loyalty of the individual to the state rather than a particular ethnic group. In such cases, the actors can belong to multi-ethnic group what ties them together is being a citizen of a particular state. However, ethno-nationalism attempts to mobilize the members of one ethnic group for seeking a particular goal. When loyalty or cohesion to the national identity is threatened or when one ethnic group feels that their identity is repressed conflict ensues. Identity conflicts can be inter-state and intra-state; however, inter-state conflicts have decreased significantly since World War II, while intra-state conflict continues to rise with incidences of armed conflict, political violence, genocide, etc. Historians and scholars posit that World Wars I and II were fueled by nationalism, where the great powers competed against one another for land, influence, resources, and power.

However, in the later part of the $20^{\text {th }}$ century, the bloodiest conflicts that took place where within states, among different civic and ethnic cultural groups. One major example that includes both was the breakup of Yugoslavia, when the multi-ethnic country made up of 6 republics splintered across ethnic lines. As the various republics began to declare independence, the Serb dominated Yugoslav federal government acted forcefully to stop secession, especially in Croatia and Bosnia, countries that had number of ethnic Serbs living within their borders. In addition to this, there were also ferocious battles within the republics as various ethnic and secessionist groups aimed to divide the republics along ethnic lines even further. 


\section{Identity and Escalation of the Conflict}

Identity can escalate conflict when one is repressed or discriminated against compared to another. If we look throughout the globe, we can find many examples of racial and ethnic discord where one ethnic or racial group decries inequalities and injustices that they perceive to be based on unfair treatment due to their particular identity. Most members belonging to a national or ethnic group, also as discussed above tend to have common markers of culture, language and origin. However, what happens when there are those who were not socialized within the context of that group identity, such as immigrants or people who have ethnic identities which eclipse their national Identity? There can be major issues, where those groups may feel isolated, or on the margins of society. Also, people who adhere to the main national identity may harbor ill-will or feelings towards those that do not. A great example of this is second generations of Muslims of North African and the Middle Eastern decent, still struggle to fit into and the French national identity. And feel that they are treated unjustly and forced to live on the margins of society. Many in France see most of the conservative religious ideas they are raised with as incompatible with traditional French and European liberal ideas. Especially as of lately, as France has suffered terrorist attacks. Nevertheless, terrorist attacks are more complicated than bad people just want to hurt good people. It's much more complicated than this, to look at why French youth are being radicalized we have to look at the conditions in the environment from which they come after all as Folger et al (2009) points out above a lack of membership in a certain aspect is also just as important as membership.

Due to the way groups operate, it is often easy for one group to separate themselves from others, whether it is based on national identity, language, culture, etc. Often we begin to draw lines between "us" and "them" often making the "us" the more superior and this "us" mentality can be furthered and fueled by ideas like nationalism or ethnic hegemony. Nationalism or ideas of ethnic superiority may push those who identify as "us" to ostracize and ridicule those who identify as "them", for being different, which will further lead to perhaps strong animosity and in some cases lead to discrimination and repression. This falls along the lines of the idea of moral exclusion. Moral exclusion is the notion that some individuals and groups fall outside the limits of what our societal standards of what is morally right or fair. Christie et. al., (2001) explain 
that our morals spell out our senses of justice by identifying what we owe to whom, whose gets what, when, why, and to whom this does not apply or fall within our scope of justice or community morals.

Another way of considering the issue of identity gives us frames that come with a sense of morality when we feel people operate outside of this context; we feel that they do not deserve to benefit from the best aspects of our moral code, like justice. However, moral exclusion is a dangerous concept, excluding people is subject to what one particular group thinks another should have, be, or possesses for fairness. This could include, race, gender, sexuality, religion, etc. Moral exclusion can be justified often in a variety of ways and can be used to justify social and economic inequalities like structural violence. Morally excluding certain groups from societal narratives and norms of justice are great sources of conflict and often times pushes latent conflicts to escalate when those on the receiving end of moral exclusion have finally had enough.

Moral exclusion also lays the foundation for certain groups to be legally and economically exclude. This is what Gatling (1979) terms structural violence. Another way of looking at this is through the theory of structural violence. Galtang (1969) coined the theory of structural violence to explain harmful factors in societal structures that may disenfranchise or repress. "There may not be any person who directly harms another person in the structure, the violence is built into the structure and shows up as unequal power and consequently as unequal life chances" (Gatling, 1969, p. 171). These systematic aspects leave the exclude groups feeling hurt, angry, frustrated, and ignored to the point where the conflict may turn armed violence or terrorism.

\section{Identity, Conflict, and Power}

Another important aspect in understanding how identity contributes to conflict is grasping the aspects of identity and how it relates to power. One of the ways we can see and understand how identity, conflict and power work in relation to each other. Let us explore The Parable of the Tribes concept. The Parable of the Tribes concept is a social theory that paints the following scenario: a group of many neighboring tribes which, initially, live peacefully and amicably with another, until at one of these tribes becomes aggressive and attempts to conquer their neighbors. This theory maintains that the neighboring non-combative tribes have one of four outcomes: The tribe is conquered, and all its inhabitants are annihilated; The tribe is conquered, and its surviving inhabitants 
are forced to subordinate their wills to the will of the conquering tribe; The tribe flees to an inaccessible or inhospitable region, abandoning its territory, which is appropriated by the conquering tribe. The tribe resists conquest, and defeats its would-be conqueror (Smookler, 1995). The point of the parable of the tribes is that all four possible outcomes to this situation result in the expansion of the ways of power among humans, at the expense of the ways of peace. In order for the fourth option to take effect, the conquest-resisting tribe is forced to adopt at least some of the ways of power initiated by the would-be conquering tribe, because (Schmookler, 1995) argues, power can only be countered with power.

The Parable of the Tribes theory of social evolution, which shows that power is like a contaminant, a disease, which once introduced will gradually yet inexorably become universal in the system of competing societies (Smookler, 1995). More important than the inevitability of the struggle for power is the profound social evolutionary consequence of that struggle once it begins. A selection for power among civilized societies is inevitable (Smookler, 1995). Moreover, according to Schmookler (1995), any tribe at any time opting for the ways of power, or the ways of war, thereby imposes this one-way evolutionary path, sooner or later, upon all others, and the fate of the human race is thereby sealed. He further argues that, once introduced, not only do the ways of war gradually foreclose upon the ways of peace; they also progressively foreclose upon the freedom of choice.

When The Parable of the Tribe is applied to identity conflicts, it allows for a deconstruction of what some identity conflicts may actually be based around and that is a struggle for power and resources. Peoples of different identities may not be in conflict solely for the simple fact that they are different, but, because they are often times competing with one another and it is that resources, power, equality are not shared properly. After all, conflict is defined as a divergence of interests. Maintaining power is a very important as the parable of the tribe suggest, because power can only be fought with power. And power is the only way any group to protect their interest. Interest and identity are as linked as conflict and identity. Perhaps, maintaining and protecting certain interest can become very much be a part of one group's identity. Just like a group protecting and maintaining their identity may very well important to that group's interest also. As discussed above identities come with collective memories and stories. Different ethnic, cultural and religious groups all have important hallmark events, values, chosen traumas that are a defining part of that identity. 
A great example is Hitler's rise to power in Germany. Hitler exploited the fact that Germany had been punished unjustly for World War I and therefore not only had to avenge the wrong that was done to them, but, also repossess land in central Europe that they once possessed. Hitler, preached that a travesty had been committed against the German people and the German identity therefore, they had to match force with force and power with power, to have their interests met. And as The Parable of the Tribes indicates the little peace that came after World War II was destroyed by one belligerent nation's quest for power. Of course out of the four scenarios discussed the allied powers chose fight Hitler's quest for power in order to survive. And like Hitler, the Allied Powers also tied their battle against Nazi expansion to national identity. The Nazi's weren't only threatening the balance of power in the world, but, they were also threatening national identities. The evidence of identity being a central part of World War II is evident in war time propaganda, which usually consisted of material that defamed the national identities of their enemies.

\section{Identity and De-escalation of Conflict}

Since having discussed how identity can breed conflict, now it is important to discuss how identity de-escalates conflict. The same way identity can breed conflict it can de-escalate it and that is through the same collective identity process. As earlier, identities are shared among people who have collective memories, ideas, values, origins, etc. These similarities and values can be exploited to avoid conflict. Renan (1996) argues that more valuable by far than common customs posts and frontiers conforming to strategic ideas is the fact of sharing, in the past, a glorious heritage and regrets, and of having, in the future, [a shared] program to put into effect, or the fact of having suffered, enjoyed, and hoped together (p. 42). These are the kinds of things that can be understood in spite of differences of race and language. Where national memories are concerned, grief is of more value than triumphs, for they impose duties, and require common efforts (p. 42). Moving beyond the example beyond what seems to be provided as a domestic example to one in a more international context, the EU (European Union) is a great example of sharing in an identity, which therefore reduces the room for conflict. Europe before the formation of the EU had a series of wars and battles over the centuries that were based around nationalism and power. Since the formation, there is a sense of cohesion and common 
identity, where all of the member states have stake in what goes on and they work together to main their common goals and their identity as the EU. If two states were to be in a violent conflict, other EU states will suffer too as they are adjoined economically and politically. So developing and maintaining a culture of peace is very important.

\section{Conclusion}

Understanding identity and conflict, does not just help those who are studying conflict determine how identities can be used for and in neutralizing conflict, it us helps individuals, communities, societies, and nations be able to understand the nature of conflicts that may or may not be centered on different aspects of identity. In helping individuals, communities, and societies understand the nature of their conflicts that maybe identity based, we lay the foundation for possible opportunities to overcome these conflicts through dialog and discussion about what aspects of one groups identity (whether it be beliefs, notions, and norms ) threatens another. Bringing those who have different points of view together does more than just change opinions, biases, and ideas, it also provides chances for once conflicting parties to find commonalities, develop new relationships, and perhaps maybe even plan for a better future. This better future could be more fulfilled individuals, prosperous communities, or even more tolerant and accepting societies.

\section{References}

Christie, Wagner, \& winter, (2001). Peace, Conflict, and Violence: Peace Psychology for the $21^{\text {st }}$ Century. Englewood Cliffs.

Folger, J. P., Poole, M. S., \& Stutman, R. K. (2009). Working Through Conflict. Boston: Pearson.

Galtung, J. (1969). "Violence and peace." Journal of Peace Research, 167-191.

Midlarsky, M. I. (Ed.) (2000). Identity and Conflict. Ann Arbor, MI: University of Michigan Press.

Pruit, D.G., \& Kim, S.H. (2004). Social Conflict: Escalation, Stalemate, and Settlement. $3^{\text {rd }}$ Edition. New York: McGraw-Hill.

Renan, E. (1996). "What is a nation?" In Eley (Ed.), Becoming National: A Reader. New York and Oxford: Oxford University Press.

Schmookler, A. B. (1995). The Parable of The Tribes (2nd ed.). Albany, NY: SUNY Press. 